\title{
RODA FôNICA CODIFICADA
}

\author{
Orlando Volpato Filho
}

GreenWorks

E-mail: ovolpato@hotmail.com

\section{RESUMO}

A rápida detecção da posição do eixo do motor é importante em sistemas Stop/Start assistidos por combustão.

Atualmente, os sistemas de controle motor usam uma roda fônica com 58 dentes, ou suas variantes, para se determinar o ângulo do motor e comandar os eventos de ignição, injeção de combustível, janela de detonação, etc.

Essa roda tem 60 dentes igualmente espaçados, com 2 dentes faltando. Outras configurações existem, porém, normalmente usam a marca de referência em uma única posição.

Esse conceito apresenta os problemas: 1) pode ser necessário até uma volta completa do motor para encontrar a marca de referência e 2) normalmente não se pode atribuir eventos síncronos na marca de referência.

Se propõe uma roda fônica codificada onde a marca de referência está espalhada em toda a sua circunferência, e os dentes representam símbolos, p. ex. 0 e 1, identificáveis pela largura do dente. Um tipo de transição, p. ex. borda de subida, ocorre em intervalos regulares e é usada para se medir o ângulo do motor.

O código usado tem propriedade ótima de auto sincronização, p. ex. T-Codes, que é largamente usado em algorítimos de compressão de imagens e texto. A sincronização é obtida em menos de $1 / 9$ de volta do motor.

\section{INTRODUÇÃO}

Desde que o motor de combustão teve os eventos de ignição, e posteriormente, injeção de combustível, controlados por um módulo de controle eletrônico, mesmo que analógico, houve a necessidade de se saber a posição do eixo motor de modo a se aplicar a ignição e/ou injeção nos momentos em que o desempenho do motor é otimizado.

A posição do motor, também, é usada nas lógicas de controle de detonação, que normalmente analisam as vibrações do bloco do motor em regiões de ângulo motor específicas, de modo a se minimizar a interferência de ruídos, como, por exemplo, de abertura de fechamento de válvulas. 
No início do uso de módulos eletrônicos para o controle de motor se usava engrenagens já existentes, como, por exemplo, a engrenagem da polia dentada ligado ao eixo de comando de válvulas com um sensor de rotação associado, normalmente do tipo relutância variável.

Como os dentes dessa engrenagem eram uniformemente distribuídos, se fazia necessário, uma outra polia, e o respectivo sensor, ligado ao eixo do motor, com um único dente, denominado de marca de referência, para indicar um ângulo associado ao ponto morto superior de um dos cilindros, normalmente o de número 1; de modo a se saber o ângulo do motor através da composição da informação dos dois sensores.

Com o advento de módulos eletrônicos micro controlados de maior capacidade computacional, de modo a se economizar um sensor de rotação, e os respectivos acessórios de montagem, além de cabos e conectores, substituiu-se a polia com a marca de referência por uma polia de múltiplos dentes e com a marca de referência feita através da ausência de um ou mais dentes. Essa polia é popularmente chamada de roda fônica, derivado do termo em italiano.

Normalmente o número de dentes é divisível pelo número de cilindros do motor, de modo a se ter uma simetria no algoritmo de controle. A marca de referência fica a uma distância tal do ponto morto superior do cilindro de número um, de modo que o módulo eletrônico tem tempo de realizar os cálculos necessários para os eventos de controle do motor.

Apenas se sabe o ângulo do motor nas transições dos dentes, para se ter evento motor em ângulos intermediários, se faz necessária uma interpolação no tempo entre transições do dente anterior.

Como a aceleração do eixo do motor é alta próxima ao evento de combustão, houve a tendência de se usar um grande número de dentes; porém, isso acarreta tempos entre as bordas de dentes pequenos, então, considerando-se um compromisso entre precisão do ângulo de controle e a capacidade de processamento do módulo eletrônico um número dentes comum é 60 e a marca de referência se faz eliminando dois dentes. Ver figura 1.

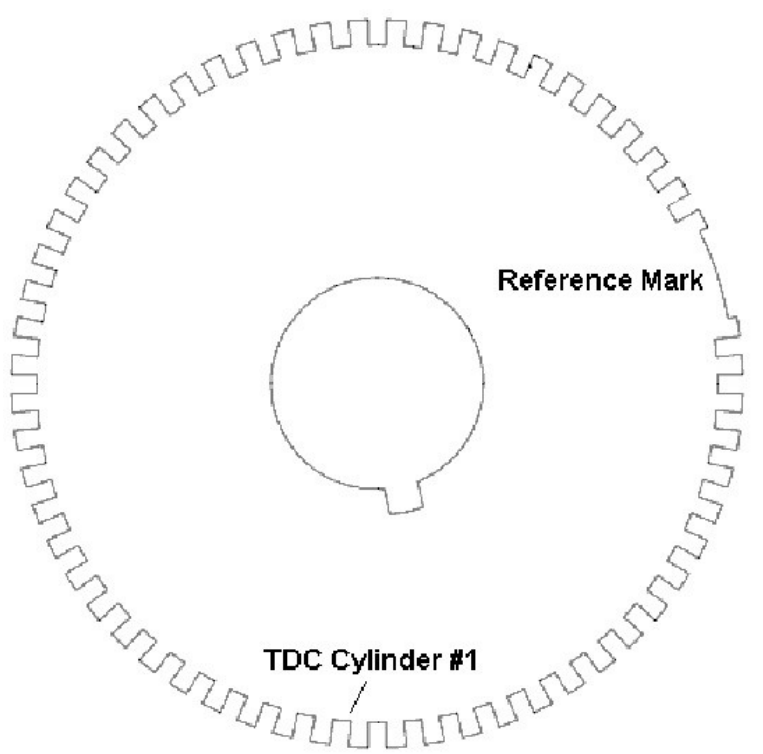

Figura 1: Exemplo de roda fônica com 60-2 dentes 
Existem rodas fônicas com diversos números de dentes, sendo os mais comuns 60-2, 36-2 e 24-1 dentes. A Renault usava uma roda fônica, onde ao invés de se eliminar dois dentes, se colocava um dente maior no lugar de 3 dentes, mas a estratégia de se detectar a marca de referência era a mesma. Ver figura 2 para um outro exemplo de roda fônica, de 24 dentes, com 2 marcas de referência implementadas com uma largura de dente bem inferior ou superior aos outros dentes uniformemente distribuídos, já que é montada no eixo de comando de válvulas.

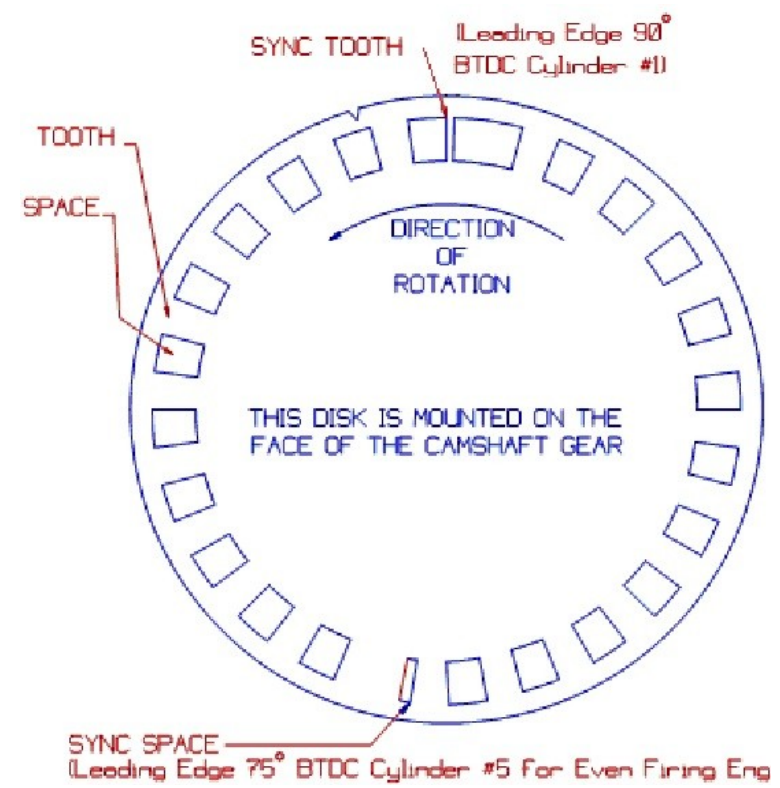

Figura 2: Exemplo de roda fônica com 24 dentes e 2 marcas de referência

A desvantagem desse tipo de roda fônica é que se precisar encontrar a marca de referência antes de se ter certeza sobre a posição do motor, e isso poderia atrasar o início de aplicar eventos de injeção síncrona de combustível e de ignição por até uma volta completa do motor.

Outra desvantagem é que, na marca de referência, por não se ter as bordas de dente como referência exata de ângulo do motor, normalmente não poderia ter eventos síncronos nessa região, limitando a capacidade de controle e muitas vezes se fazendo necessário a verificação de valores de calibração para se certificar que essa restrição não estava sendo violada.

Veja na figura 3 um exemplo de sincronização referente à roda fônica da figura 1.

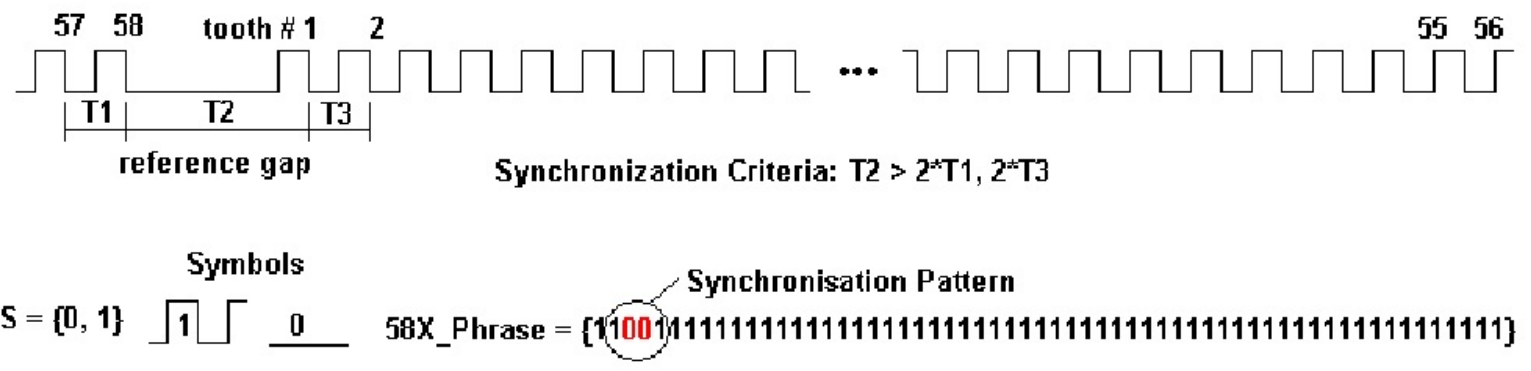

Figura 3: representação física e simbólica de uma roda fônica com 60-2 dentes

Muitas vezes, soluções não elegantes de software foram usadas para se contornar essa limitação. 
Com a legislação de emissão de poluentes exigindo limites cada vez mais apertados, e ultimamente, com o maior interesse em se reduzir o consumo de combustível, com tecnologia de stop/start, por exemplo, se lançou mão de artifícios como o de se salvar a posição do motor quando este é desligado. Porém, quando o motor está quase parando, normalmente há uma oscilação para a frente e para trás do eixo motor e a contagem da posição pode estar errada.

Lógicas sofisticadas têm sido elaboradas para se minimizar esse erro, ou também o uso de sensores de rotação duplo hall, micro controlados, e portanto mais caros, com capacidade de detecção do sentido de rotação, com uma correspondente sofisticação da lógica no software de processamento desse sensor.

Uma solução elegante para esses problemas é o uso de uma roda fônica codificada, com capacidade de se adquirir a posição do eixo motor numa pequena fração de volta.

No capítulo a seguir será explicado o conceito de roda fônica codificada.

\section{RODA FÔNICA CODIFICADA}

O conceito de roda fônica codificada faz uma ruptura com conceitos antigos de se determinar a posição do eixo motor, que tem evoluído de forma incremental através do uso de algoritmos cada vez mais sofisticados, com tratamentos diferenciados quando se está parando o motor e se usando sensores mias complexos, porém, usando-se o velho conceito de se ter uma única marca de referência.

$\mathrm{Na}$ roda fônica codificada se continua tendo um número de dentes divisível pelo número de cilindros do motor, porém, não se tem eliminação de dentes para a formação de uma marca de referência. Dessa forma se tem $\mathrm{N}$ dentes igualmente espaçados, onde uma das transições, de subida ou de descida, está associada ao ângulo correto do motor. A outra transição, de descida ou de subida, é variável, de modo que se pode associar um símbolo, 1 ou 0 , facilmente detectável pelo módulo de controle motor.

Para rodas fônicas com diâmetro maior, com menor quantidade de dentes, ver figura 2, onde o a distância entre dentes é bem maior que a resolução espacial do sensor de rotação, pode-se ter códigos derivados a partir de 3 ou mais símbolos (p. Ex: 1, 2, 3), de modo a se ter uma sincronização mais rápida.

Combinações de símbolos são usadas para se formar códigos únicos, de modo que a roda fônica será uma combinação de marcas de referência distribuídas ao longo de sua circunferência, sem falhas de dentes.

A seguir uma descrição de como os códigos são formados.

\subsection{Códigos Auto-Sincronizáveis}

Com a evolução da teoria computacional, usada para se resolver problemas de criptografia e de limitação de capacidade de armazenamento e de banda de transmissão de dados, criaram-se algoritmos de compactação de dados. Nesses 
algoritmos, símbolos que aparecem com maior frequência num texto, por exemplo, são substituídos com símbolos identificáveis que têm um número menor de bits.

Um dos códigos possíveis foi desenvolvido em 1952 por David A. Huffman que era, na época, estudante de doutorado no MIT, e foi publicado no artigo "A Method for the Construction of Minimum-Redundancy Codes".

Essa codificação usa as probabilidades de ocorrência dos símbolos no conjunto de dados a ser compactado para determinar códigos de tamanho variável para cada símbolo. Uma árvore binária completa, chamada de árvore de Huffman é construída recursivamente a partir da junção dos dois símbolos de menor probabilidade, que são então somados em símbolos auxiliares e estes símbolos auxiliares recolocados no conjunto de símbolos [1].

O processo termina quando todos os símbolos foram unidos em símbolos auxiliares, formando uma árvore binária. A árvore é então percorrida, atribuindo-se valores binários de 1 ou 0 para cada aresta, e os códigos são gerados a partir desse percurso. A codificação de Huffman tem desempenho ótimo quando as probabilidades dos símbolos são potências negativas de dois (i.e. 0.5 ; 0.25 ; etc).

A codificação gerada tem também a garantia de ser não ambígua, pois nenhum código pode ser o prefixo de outro código. Isso não ocorre caso se tenha um código com um número fixo de bits, pois se se inicia a decodificação no meio de um símbolo, no bit 2, por exemplo, a sequência, tomada a partir desse ponto faz sentido e os símbolos são todos decodificados com erro.

Esse era um problema no armazenamento serial de dados (como num disco rígido) ou na transmissão de dados (como numa comunicação por telefonia celular digital) onde algum bit da informação poderia ser corrompida por erros de leitura ou interferência. Essa não ambiguidade de símbolos dá a essa codificação a capacidade de se recuperar de erros.

Para a solução desse problema foram desenvolvidos codificações derivadas dos códigos de Huffman, porém, com características ótimas de tolerância a erros e autosincronização.

O conceito de roda fônica codificada usa uma classe de codificação denominada TCodes, assim denominada por ter sido desenvolvida por Mark Titchener em1984, como sua tese de doutorado na Universidade de Auckland.

A principal característica dos T-Codes é sua forte propriedade de auto-sincronização, resultado da seu método de construção recursiva [2].

Considerando-se que a leitura dos códigos, para efeito de sincronização, pode ser feita a partir de qualquer ponto, o número médio de símbolos necessários para se atingir a sincronização é menor do que 1.5 x o número médio de símbolos do conjunto de códigos usados [3]. 
Na figura 4, abaixo, vê-se uma representação em árvore do processo de construção de T-Codes.

\subsection{Projeto da Roda Fônica Codificada}

Para o projeto da roda fônica codificada se escolhe os símbolos de menor tamanho de modo que o número total de termos do alfabeto $(0,1)$ usados correspondam ao número de dentes desejado. Por exemplo: o símbolo 110 corresponde a 3 dentes.

Os símbolos também podem ser justapostos em qualquer ordem sem que isso afete a sua eficiência, porém, pode-se usar certas peculiaridades do motor de modo a se acelerar o processo de sincronização, que será visto no próximo item.
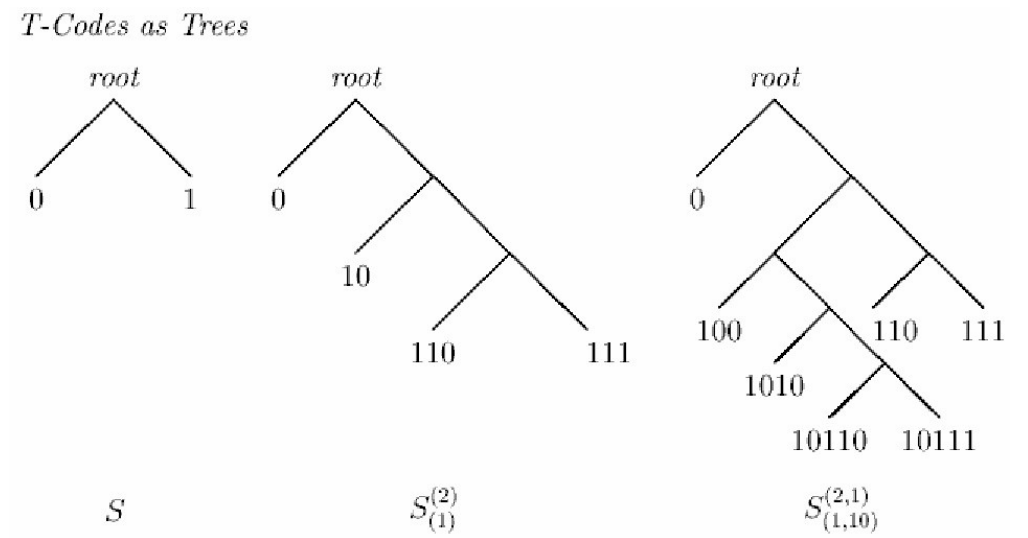

Figura 4: Exemplo de construção de T-Codes através do aumento da árvore

Na figura 5, abaixo, se tem um exemplo de roda fônica codificada que pode substituir a roda fônica mostrada na figura 1.

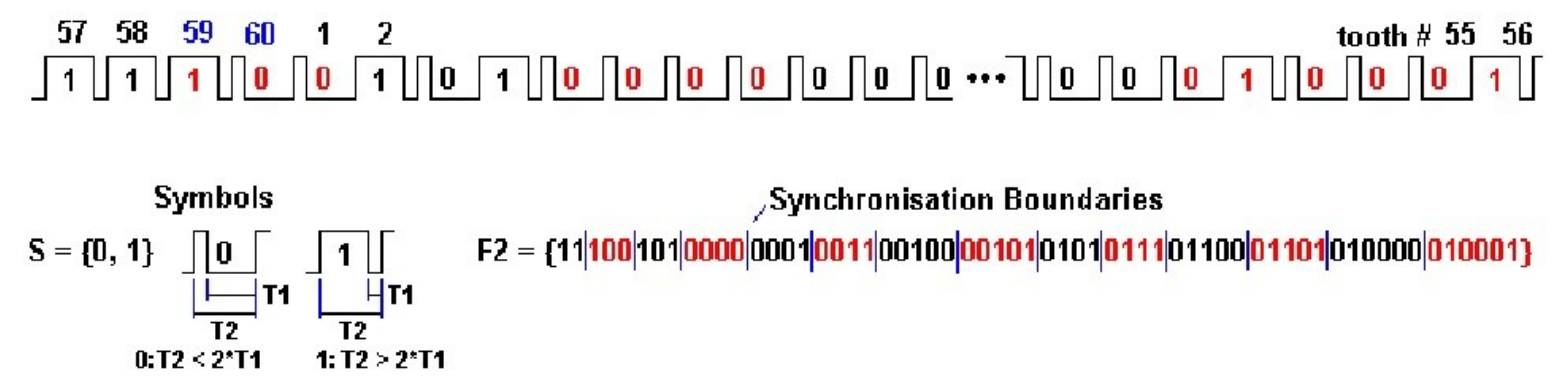

Figura 5: representação física e simbólica de um exemplo de roda fônica codificada com 60 dentes

Na figura 6 e 7, abaixo, se tem exemplos de sincronização da roda fônica codificada como na figura 5.

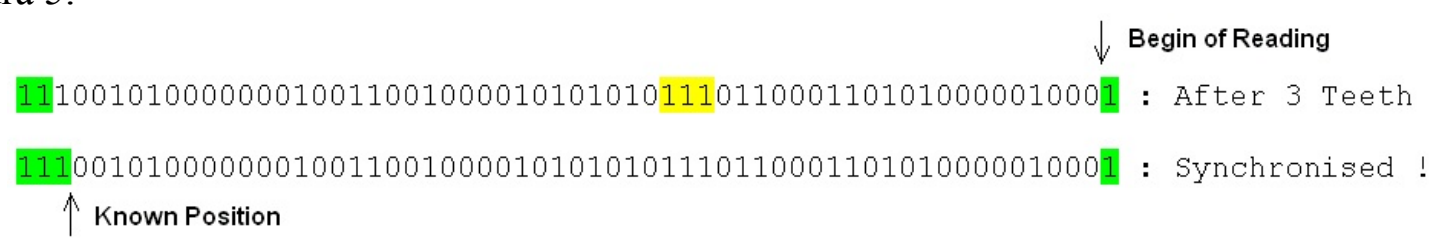

Figura 6: exemplo de sincronização de roda fônica codificada com 60 dentes, melhor caso. 


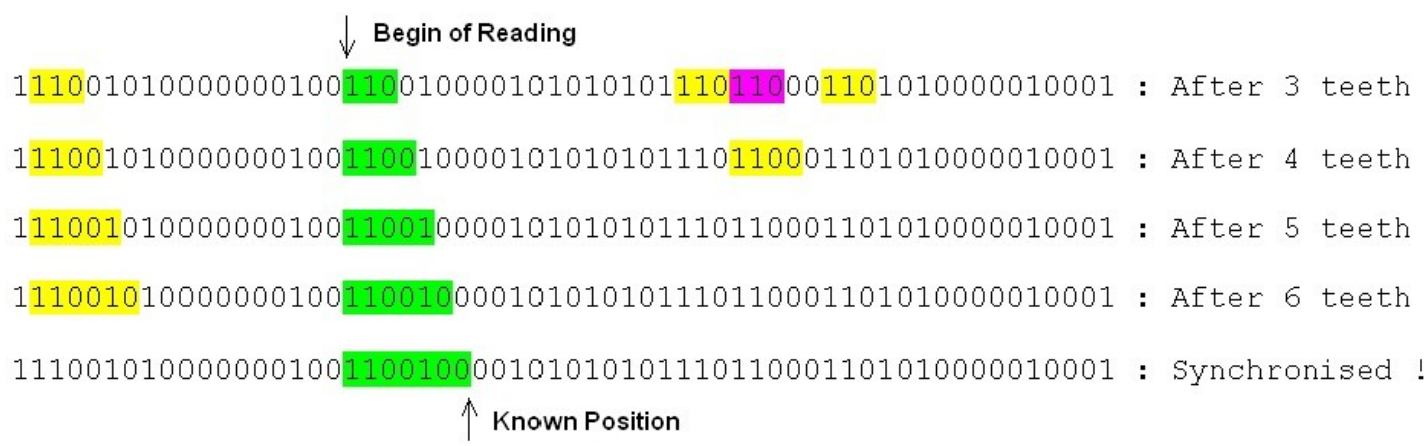

Figura 7: exemplo de sincronização de roda fônica codificada com 60 dentes, caso típico.

Na figura 8, abaixo, se tem um exemplo de roda fônica codificada, que pode substituir a roda fônica mostrada na figura 2. Como os dentes são bem mais largos do que a definição espacial do sensor de rotação, usou-se lógica terciária, onde o alfabeto tem 3 símbolos $(0,1$ e 2). Deve-se também levar em conta a dinâmica da velocidade de rotação instantânea de modo que os símbolos possam ser lidos de forma inequívoca.

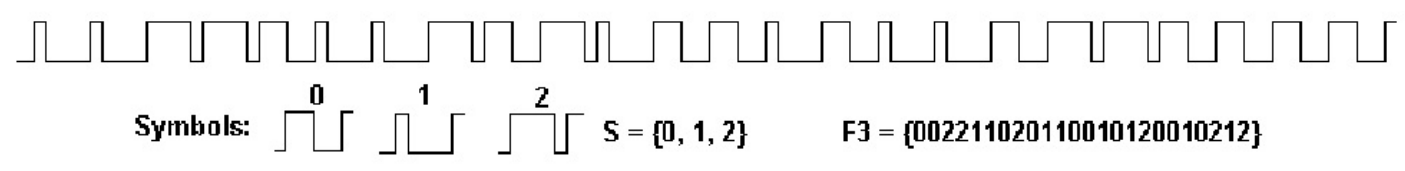

Figura 8: representação física e simbólica de um exemplo de roda fônica codificada com 24 dentes

\subsection{Otimização da Velocidade de Sincronização}

Pode-se reduzir o número médio de leituras (dentes) necessárias para se conseguir a sincronização levando-se em conta que o motor tem posições naturalmente preferenciais de parada em função do torque de compressão dos cilindros.

Quando o cilindro se move na direção do ponto morto superior o eixo a compressão do ar oferece um torque negativo, quando o pistão passa do ponto superior, a energia armazenada no ar comprimido faz um torque positivo, avançando o eixo do motor; durante a parada do motor isso ocorre até que a energia cinética do motor em movimento é gasta e o motor para numa posição onde o torque é próximo de zero logo após a descompressão de um cilindro [4].

Na figura 5 se vê um gráfico com o torque devido à compressão do ar em um motor de 4 cilindros.

Na figura 6 pode se ver um gráfico mostrando posições de repouso do eixo motor para 50 experimentos onde o combustível foi cortado em posições aleatórias do motor [5].

Tomando-se vantagem dessa característica do motor pode-se posicionar os códigos de menor tamanho numa posição imediatamente após essas posições preferenciais de repouso. Com isso, a probabilidade de se encontrar um código pequeno assim que o motor é colocado em 
movimento é maior, resultando em sincronizações mais rápidas, menor do que um décimo de volta.

Os códigos restantes podem ser posicionados de modo a se ter o centro de massa mais próximo do centro geométrico da roda fônica, dessa forma pode-se simplificar, ou mesmo, eliminar o balanceamento da roda fônica, pois estará balanceada por projeto.

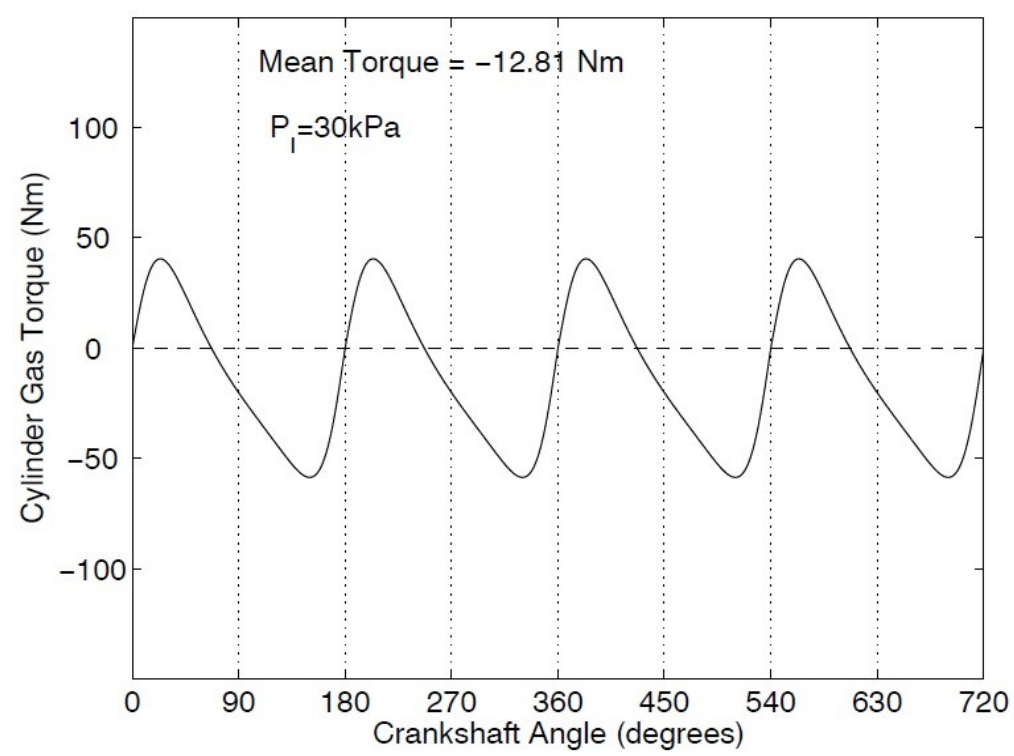

Figura 5: Gráfico de torque de compressão gasosa de um motor de 4 cilindros

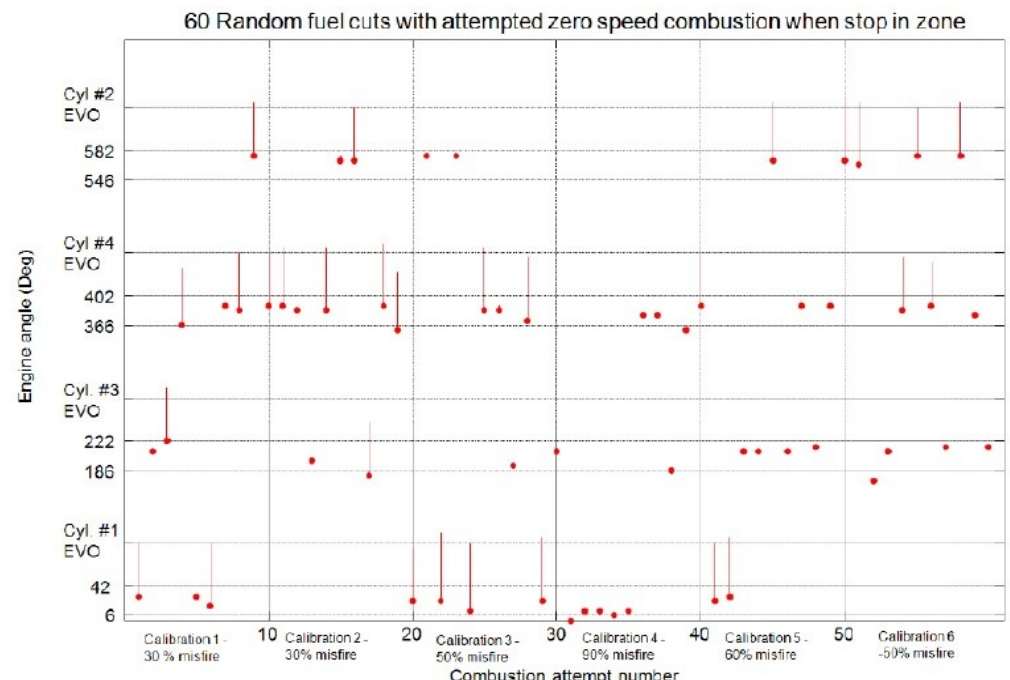

Figura 6: Gráfico da posição de repouso do eixo motor

\section{CONCLUSÃO}

Foi proposto um conceito novo de roda fônica codificada, usando-se T-Codes, onde a marca de referência não se faz com a retirada de alguns dentes, porém, usando-se códigos distribuídos ao longo do seu perímetro. 
Uma roda fônica assim constituída pode sincronizar em uma fração do ângulo motor, especialmente se se posicionar os códigos mais curtos logo após as posições de repouso naturais do motor após seu desligamento. Para uma roda fônica de 60 dentes, a sincronização ocorre, em média após se ler 6 dentes; considerado-se uma roda onde os códigos mais curtos são posicionados estrategicamente considerando-se as posições naturais de parada do motor.

Uma das bordas fica em posições angulares bem estabelecidas, ao passo que a outra borda ocorre em posições que definem cada símbolo. Desse modo a lógica de alocação de eventos síncronos pode ser feito de forma elegante, sem se ter regiões proibidas.

Uma roda fônica codificada pode simplificar as lógicas necessárias para a obtenção de menores emissões de poluentes e um menor consumo de combustível tal como a lógica de stop/start.

\section{REFERÊNCIAS}

[1] Codificação de Huffman, disponível em http://pt.wikipedia.org/wiki/Codificação de Huffman Acesso em: 20 de maio de 2013

[2] GÜNTHER, Ulrich. "Robust Source Coding with Generalized T-Codes". PhD thesis, The University of Auckland, February 1998.

[3] HIGGIE, G.R.: "Analysis of the variable length self synchronizing codes called T-codes". $\mathrm{PhD}$ thesis, University of Auckland, New Zealand, April 1991.

[4] McDonald, D., "Engine Position Tracking at Shutdown," SAE Technical Paper 2005-010048, 2005, doi:10.4271/2005-01-0048

[5] Mueller, M., "Engine Stop Position Estimation," SAE Int. J. Engines 5(2):602-607, 2012, doi:10.4271/2012-01-0720 